\title{
Плазмохимическое осаждение алмазоподобных пленок на поверхности монокристаллического высоколегированного алмаза
}

\author{
() А.И. Охапкин, П.А. Юнин, М.Н. Дроздов, С.А. Королев, С.А. Краев, Е.А. Архипова, \\ Е.В. Скороходов, П.А. Бушуйкин, В.И. Шашкин
}

Институт фризики микроструктур Российской академии наук, 603087 Афонино, Кстовский район, Нижегородская обл., Россия

E-mail: andy-ohapkin@yandex.ru

Поступила в Редакцию 24 апреля 2019 г.

В окончательной редакции 29 апреля 2019 г.

Принята к публикации 29 апреля 2019 г.

\begin{abstract}
Проведено плазмохимическое осаждение алмазоподобных пленок (DLC-пленок) на монокристаллический сильно легированный бором (концентрация $\sim 10^{20} \mathrm{~cm}^{-3}$ ) алмаз $p$-типа проводимости в плазме $\mathrm{CH}_{4}+\mathrm{Ar}$. Скорость осаждения составила 7 нм/мин. Детально исследованы элементный состав и свойства полученных пленок. Пленки оказались обогащенными водородом, имели плотность 2.4 г/см ${ }^{3}$ и ультрагладкую поверхность (шероховатость $0.4 \pm 0.2 \mathrm{Hм}$ ).
\end{abstract}

Ключевые слова: алмазоподобный углерод, плазмохимическое осаждение, монокристаллический алмаз.

DOI: 10.21883/FTP.2019.09.48129.12

\section{1. Введение}

В последнее время в литературе все чаще стали появляться работы на тему использования алмазных структур в процессе изготовления полевых транзисторов (field-efect transistors, FETs) [1-4]. Технологически важной при этом является стадия нанесения тонких диэлектрических слоев на поверхность алмаза, которые обеспечивали бы хорошие изоляционные характеристики. В роли таких слоев могут выступать оксид алюминия [1-5], нитрид кремния и оксид циркония [6], оксид молибдена [7] и др. Однако особый интерес в плане применения в качестве диэлектриков представляют собой пленки алмазоподобного углерода (diamond like carbon, DLC), содержащие как алмазные $\left(s p^{3}\right)$, так и графитоподобные связи $\left(s p^{2}\right)$. Являясь родственными алмазу материалаMи, DLC-пленки характеризуются высокими химической стойкостью и твердостью [8]. Это позволяет использовать их в роли защитных покрытий для MEMS-датчиков (micro-electro-mechanical systems) [9] и в FETs [10].

Одним из надежных методов получения однородных и морфологически гладких DLC-покрытий является метод PECVD (plasma-enhanced chemical vapor deposition) [11,12]. Его улучшенный вариант осаждение в плазме индуктивно-связанного разряда (ICPCVD, inductively coupled plasma chemical vapor deposition) [13-15]. В ICPCVD благодаря плотной плазме $\left(\sim 10^{13}\right.$ реакционных частиц в $\left.1 \mathrm{~cm}^{3}\right)$ удается поддерживать высокую скорость процесса при пониженных температурах без увеличения емкостной мощности. Непосредственным источником углерода обычно выступает газообразный метан, реже ацетилен. В частности, в работе [13] описан процесс осаждения алмазоподобных пленок методом ICPCVD в плазме $\mathrm{CH}_{4}$ и $\mathrm{CH}_{4}+\mathrm{H}_{2}$. Изучено влияние толщины пленок DLC на их оптиче- ские, электрические и структурные свойства. Качество пленок исследовалось методами рамановской спектроскопии, атомно-силовой микроскопии (АСМ) и спектроскопической эллипсометрии. В исследуемых пленках DLC $s p^{3}$-фракция составляла от 60 до 70\%. Полученные образцы характеризовались показателем преломления от 2.03 до 2.1 и коэффициентом экстинции от 0.09 до 0.12. В [14] установлено, что оптимальное значение емкостной мощности, при которой удалось получить алмазоподобные покрытия с гладкой поверхностью и высоким содержанием $s p^{3}$-фазы, составило 70 Вт. Анализ спектров испускания плазмы методом оптической эмиссионной спектроскопии показал, что возрастание индуктивной мощности приводит к увеличению степени ионизации прекурсора $\mathrm{CH}_{4}$ и скорости процесса в целом. В [15] использование отрицательного потенциала на кремниевой подложке по сравнению с положительным в процессе роста DLC-пленок привело к значительному уменьшению содержания графитовой фазы, шероховатости поверхности и увеличению твердости образцов. В работе [11] показано, как добавка аргона в плазмообразующую смесь при осаждении алмазоподобного углерода на кремнии способствует снижению доли атомарного водорода и $s p^{2}$-гибридизованного углерода за счет создания инертной атмосферы в реакторе и разрушения ионами $\mathrm{Ar}^{+}$графитовых колец в процессе роста. Выводы были сделаны в результате сравнения данных FTIR (fourier-transform infrared spectroscopy) и данных спектроскопии рамановского рассеяния (соотношение интенсивностей $D$ - и $G$-пиков). В [12] методом рамановской спектроскопии установлено, что увеличение концентрации аргона в плазме $\mathrm{CH}_{4}+\mathrm{Ar}+\mathrm{H}_{2}$ от 25 до 63\% способствует снижению содержания $s p^{2}$-фазы углерода в DLC-пленках в 2 раза. Однако наряду с этим возрастает шероховатость поверхности. 
Так как для алмаза характерна большая глубина залегания примесей, для поддержания приемлемой концентрации носителей заряда необходимо сильно легировать подожку без потери подвижности, что является довольно сложной задачей. Существенным сдвигом в этом направлении можно считать получение $\delta$-легированного бором монокристаллического алмаза $p$-типа проводимости с высокой концентрацией носителей $[16,17]$. Однако до сих пор в литературе отсутствуют сведения о процессе осаждения DLC-пленок на поверхности монокристаллического алмаза с концентрацией примесей $\sim 10^{20} \mathrm{~cm}^{-3}$ и выше. Упоминается лишь о применении DLC [18] в качестве промежуточных областей между металлом и алмазом, улучшающих омические контакты, без описания их структурных и морфологических свойств. В связи с этим получение DLC-пленок на монокристаллическом сильно легированном алмазе с последующим детальном исследовании их свойств является весьма актуальным.

\section{2. Методика эксперимента}

Плазмохимическое осаждение пленок DLC выполнено на установке Oxford Plasmalab 80 Plus в реакторе с двумя плоскопараллельными электродами и источником индуктивно-связанной плазмы частотой 13.56 МГц.

Толщину, плотность и шероховатость пленок измеряли методом малоугловой рентгеновской рефлектометрии. Элементный состав DLC-покрытий установили в результате послойного анализа методом вторично-ионной масс-спектрометрии (ВИМС) с высоким разрешением по глубине. Дополнительно поверхность пленок была изучена методами интерферометрии белого света, АСМ и сканирующей электронной микроскопии. Структурный состав пленок DLC определен из анализа спектров комбинационного рассеяния при возбуждении аргоновым лазером с длиной волны 514.5 нм в диапазоне рамановского сдвига от 1000 до $2000 \mathrm{~cm}^{-1}$. Электрофизические свойства алмазоподобных покрытий определены путем измерения вольт-амперных характеристик (BAX) и емкости между проводящей подложкой и контактами на поверхности DLC. Для формирования контактов была проведена фотолитография с нанесением металлической пленки из $\mathrm{Al}$ методом электронно-лучевого напыления.

\section{3. Результаты и обсуждение}

На поверхности монокристаллического высоколегированного алмаза (концентрация бора $\sim 10^{20} \mathrm{~cm}^{-3}$ ) и кремния (для сравнения) в плазме метана и аргона были получены первые образцы DLC-покрытий. Скорость осаждения пленок на кремнии при использовании чистого метана составила 7.4 нм/мин. При добавке аргона скорость осаждения составила 7.8 нм/мин для кремния и 7 нм/мин для монокристаллического алмаза. Пленки, выращенные на монокристалле алмаза, оказались ультрагладкими с шероховатостью $\sigma=(0.4 \pm 0.2)$ нм. На

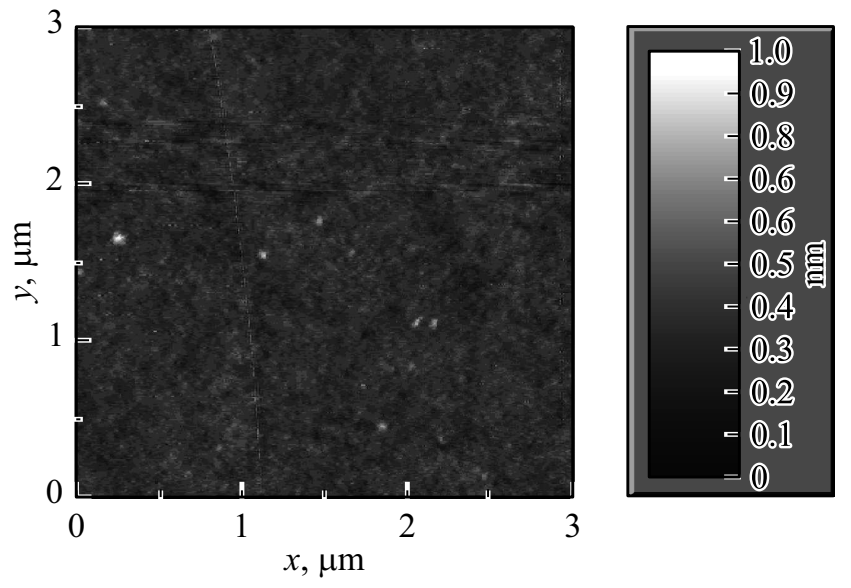

Рис. 1. ACM-изображение поверхности пленки DLC, осажденной на монокристаллическом алмазе.

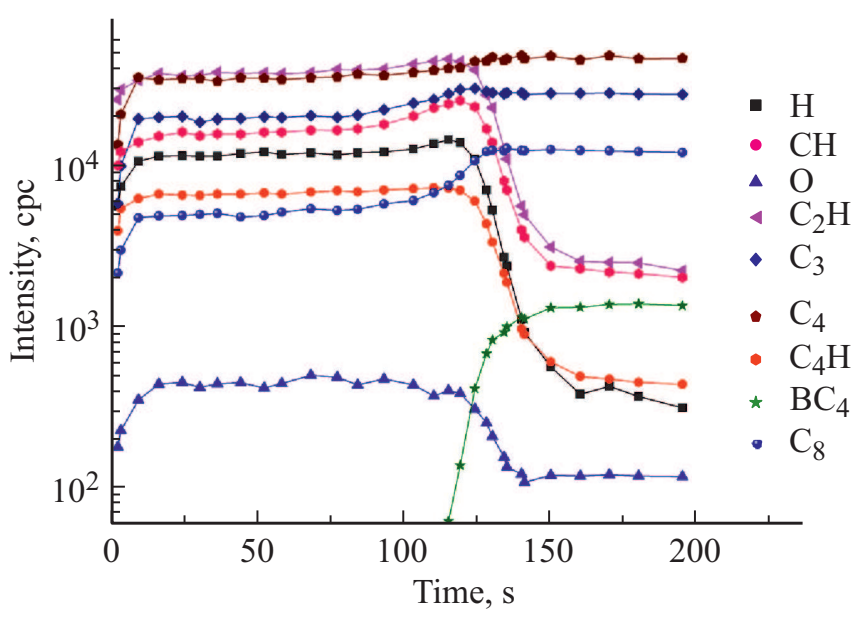

Рис. 2. Профиль распределения элементов (полученный послойным BИMC-анализом) по глубине пленки DLC, осажденной на монокристаллическом алмазе.

участке площадью 9 мкм ${ }^{2}$ шероховатость поверхности составила 0.06 нм (рис. 1) при перепаде высот $0.3 \mathrm{Hм}$ (по данным АCM). Пленки, полученные на алмазе, оказались более плотными (плотность 2.4 г $/ \mathrm{cm}^{3}$ ), чем на кремнии (плотность 1.9 г/ $\mathrm{cm}^{3}$ ). При этом на поверхности образцов, осажденных на $\mathrm{Si}$, имелись крупные неоднородности диаметром > 100 нм. В пленках, полученных на алмазе, таких дефектов не было.

В результате анализа химического состава выяснилось, что в спектре пленок представлены те же линии вторичных ионов, что и для алмазной структуры, за исключением линии $\mathrm{BC}_{4}$ ввиду отсутствия борсодержащей примеси в DLC (рис. 2). Кроме того, все образцы содержали значительное количество водорода как в свободном, так и в связанном с углеродом состоянии, что характерно для пленок, выращенных методом низкотемпературного плазмохимического осаждения [13]. Повышенное содержание кислорода в DLC по сравнению с 
Электрофизические характеристики DLC-пленок, осажденных на кремнии

\begin{tabular}{c|c|c|c}
\hline Толщина, нм & $\rho, 10^{11} \mathrm{Oм} \cdot \mathrm{cm}$ & $E_{\mathrm{br}}, 10^{7} \mathrm{~B} / \mathrm{cm}$ & $\varepsilon$ \\
\hline 13 & $0.5-0.7$ & $0.5-0.6$ & 3.3 \\
43 & $3.3-3.7$ & $0.2-0.3$ & 4.4 \\
108 & $3.3-3.4$ & $0.2-0.4$ & 4.6
\end{tabular}

алмазом объясняется очисткой камеры реактора кислородной плазмой перед проведением процесса осаждения.

В рамановском спектре пленки DLC, осажденной на кремнии, присутствовало два характерных пика: пик $G$ при $1513 \mathrm{~cm}^{-1}$, отвечающий колебаниям $s p^{2}$-связей углерода, и пик $D$ при $1303 \mathrm{~cm}^{-1}$, связанный с наличием нанометровых графитовых доменов [19]. Сдвиг положений характерных пиков в меньшие волновые числа (по сравнению с нанокристаллическим графитом) наряду с низким соотношением их интенсивностей $(0.3)$ свидетельствует об аморфном состоянии углерода с высоким содержанием $s p^{3}$-фракции (стадия 2 согласно модели Феррари-Робертсона) [20].

Удельное сопротивление $(\rho)$ DLC-пленок, осажденных на кремнии, варьировалось в диапазоне $(0.5-3.7) \cdot 10^{11} \mathrm{Oм} \cdot$ см в зависимости от их толщины (данные приведены в таблице). Поле пробоя составило $E_{\mathrm{br}}=(0.2-0.6) \cdot 10^{7} \mathrm{~B} / \mathrm{cm}$, диэлектрическая проницаемость $\varepsilon=3.3-4.6$.

\section{4. Заключение}

В работе проведено плазмохимическое осаждение пленок DLC на монокристаллический сильно легированный бором (концентрация $\sim 10^{20} \mathrm{~cm}^{-3}$ ) алмаз $p$-типа проводимости в индуктивно-связанной плазме $\mathrm{CH}_{4}+\mathrm{Ar}$. Скорость осаждения составила 7 нм/мин. Полученные покрытия содержали значительное количество водорода, имели хорошие морфологические, структурные и диэлектрические характеристики $(\sigma=(0.4 \pm 0.2)$ нм, $\left.\rho=(0.5-3.7) \cdot 10^{11} \mathrm{Oм} \cdot \mathrm{cm}\right)$.

Плазмохимическое осаждение пленок DLC и измерения их характеристик проводились на оборудовании ЦКП ИФМ РАН „Физика и технология микро- и наноструктур“.

\section{Финансирование работы}

Осаждение и исследование слоев DLC выполнено при поддержке гранта Президента для молодых кандидатов наук МК-3450.2019.2. В части развития методики ВИМС работа поддерживалась проектом РФФИ № 18-02-00565.

\section{Список литературы}

[1] S. Imanishi, K. Horikawa, N. Oi, S. Okubo, T. Kageura, A. Hiraiwa, H. Kawarada. IEEE Electron Dev. Lett., 40 (2), 279 (2019).

[2] X. Yu, J. Zhou, C. Qi, Z. Cao, Y. Kong, T. Chen. IEEE Electron Dev. Lett., 39 (9), 1373 (2018).

[3] N.C. Saha, M. Kasu. Diamond Relat. Mater., 91, 219 (2019).

[4] C.J. Zhou, J.J. Wang, J.C. Guo, C.Yu, Z.Z. He, Q.B. Liu, X.D. Gao, S.J. Cai, Z.H. Feng. Appl. Phys. Lett., 114, 063501 (2019).

[5] TT. Pham, J. Pernot, G. Perez, D. Eon, E. Gheeraert, N. Rouger. IEEE Electron Dev. Lett., 38 (11), 1571 (2017).

[6] W. Wang, K. Fu, C. Hu, F.N. Li, Z.C. Liu, S.Y. Li, F. Lin, J. Fu, J. Wang, H.X. Wang. Diamond Relat. Mater., 69, 237 (2016).

[7] Z.Y. Ren, J.F. Zhang, J.C. Zhang, C.F. Zhang, S.R. Xu, Y. Li, Y. Hao. IEEE Electron Dev. Lett., 38 (6), 786 (2017).

[8] J. Robertson. Adv. Phys., 35 (4), 317 (1986).

[9] R. Bandorf, H. Luthje, T. Staedler. Diamond Relat. Mater., 13 (4-8), 1491 (2004).

[10] K.M. Tan, W.W. Fang, M. Yang, T.Y. Liow, R.T.-P. Lee, N. Balasubramanian, Y.C. Yeo. IEEE Electron Dev. Lett., 29 (7), 750 (2008).

[11] J. Kim, C. Lee. J. Korean Phys. Soc., 42, 956 (2013).

[12] R.G. Toro, P. Calandra, B. Cortese, T. de Caro, M. Brucale, A. Mezzi, F. Federici, D. Caschera. Surf. Interfaces, 6, 60 (2017).

[13] W. Oleszkiewicz, W. Kijaszeka, J. Gryglewicza, A. Zakrzewski, K. Gajewskic, D. Kopiecc, P. Kamyczekd, E. Popkod, M. Tlaczalaa. Electron Technology Conf. (2013, Ryn, Poland) [Proc. SPIE, 8902, 89022H (2013)].

[14] W. Oleszkiewicz, J. Markowski, R. Srnanek, W. Kijaszek, J. Gryglewicz, J. Kovac, M. Tlaczalaa. Optica Applicata, 43 (1), 109 (2013).

[15] J. Zhou, I.T. Martin, A. Reed, E. Adams, D. Liu, E. Fisher. Plasma Sources Sci. Technol., 15, 714 (2006).

[16] A.L. Vikharev, A.M. Gorbachev, M.A. Lobaev, A.B. Muchnikov, D.B. Radishev, V.A. Isaev, V.V. Chernov, S.A. Bogdanov, M.N. Drozdov, J.E. Butler. Phys. Status Solidi RRL, 10 (4), 324 (2016).

[17] Е.А. Суровегина, Е.В. Демидов, М.Н. Дроздов, А.В. Мурель, О.И. Хрыкин, В.И. Шашкин, М.А. Лобаев, А.М. Горбачев, А.Л. Вихарев, С.А. Богданов, В.А. Исаев, А.Б. Мучников, В.В. Чернов, Д.Б. Радищев, Д.Е. Батлер. ФТП, 50 (12), 1595 (2016).

[18] A. Galbiati, S. Lynn, K. Oliver, F. Schirru, T. Nowak, B. Marczewska, J.A. Duenas, R. Berjillos, I. Martel, L. Lavergne. IEEE Trans. Nucl. Sci., 56 (4), 1863 (2009).

[19] R. Kalisha, Y. Lifshitz, K. Nugent, S. Prawer. Appl. Phys. Lett., 74 (20), 2936 (1999).

[20] A.C. Ferrari, J. Robertson. Phys. Rev. B, 64, 075414 (2001).

Редактор Л.В. Шаронова

\section{Конфликт интересов}

Авторы заявляют, что у них нет конфликта интересов. 


\section{Plasma-chemical deposition of DLC films \\ on the surface of monocrystalline high doped diamond}

A.I. Okhapkin, P.A. Yunin, M.N. Drozdov, S.A. Korolyov, S.A. Kraev, E.A. Arkhipova, E.V. Skorokhodov,

P.A. Bushuykin, V.I. Shashkin

Institute for Physics of Microstructures,

Russian Academy of Sciences,

603087 Afonino, Kstovsky district,

Nizhny Novgorod region, Russia

Abstract Plasma-chemical deposition of DLC films on $p$-type monocrystalline diamond high doped with boron (concentration $\sim 10^{20} \mathrm{~cm}^{-3}$ ) in $\mathrm{CH}_{4}+$ Ar plasma was carried out. The deposition rate was $7 \mathrm{~nm} / \mathrm{min}$. The elemental composition and properties of obtained films were studied. The films were hydrogen enriched, had a density of $2.4 \mathrm{~g} / \mathrm{cm}^{3}$ and ultra smooth surface (roughness of $0.4 \pm 0.2 \mathrm{~nm})$. 